\title{
Planejamento da capacidade: um estudo de caso na etapa de cortes de um frigorífico de frangos
}

Danieli Martins de Almeida almeida.dmartins@gmail.com Universidade Estadual do Paraná (UNESPAR), Campo Mourão, Paraná, Brasil

\section{Tainara Rigotti de Castro} tainararcastro@hotmail.com Universidade Estadual do Paraná (UNESPAR), Campo Mourão, Paraná Brasil

\section{Tânia Maria Coelho}

\section{coelho.tania@ymaill.com}

Universidade Estadual do Paraná (UNESPAR), Campo Mourão, Paraná, Brasil

\begin{abstract}
RESUMO
O presente trabalho possui o objetivo de planejar a capacidade da Máquina Porcionadora Dupla de Asas, na Etapa de Cortes, de uma Indústria Frigorífica, tendo como suporte o estudo de tempos. Primeiro, foi definido o tempo padrão de colocar uma asa na Máquina e comparado com o plano de produção da empresa. Em seguida, foram realizados os cálculos da capacidade disponível, efetiva e realizada, da mão de obra e da máquina. Por fim, relacionaram-se todas estas variáveis, para então definir o padrão de operação ideal da Máquina que incluía a quantidade de colaboradores, e frequência de operação da Porcionadora Dupla, de modo a atender as demandas produtivas. Com a realização do planejamento da capacidade da Porcionadora Dupla, constatou-se que a Máquina possui capacidade suficiente para atender ao plano de produção da empresa e as demandas produtivas. Para garantir isto, faz-se necessário o cumprimento do padrão de operação da Máquina, no qual foi possível definir a quantidades de colaboradores necessários para abastecer a Porcionadora Dupla, operando em uma frequência definida de acordo com a velocidade das linhas que a antecedem.
\end{abstract}

PALAVRAS-CHAVE: Estudo de tempos. Capacidade de mão de obra. Capacidade de máquina. 


\section{INTRODUÇÃO}

"Atualmente, as empresas buscam produzir com a menor perda possível, de tempo, recursos e custos, sem deixar de atender aos desejos e necessidades dos clientes" (GONÇALEZ; WERNER, 2009, p. 121). Isso tem feito com que as empresas busquem cada vez mais um planejamento eficaz que possibilite equilibrar demanda com a oferta viabilizada pela sua capacidade de produção (LINGITZ et al., 2013). Neste contexto, estão as indústrias frigoríficas de frango, que, segundo a Confederação da Agricultura e Pecuária do Brasil (CNA Brasil, 2016), estima-se que haverá um crescimento na produção de 14 milhões de toneladas de carne de frango em 2017, para 16 milhões de toneladas em 2024.

Este cenário otimista demonstra a importância do planejamento para adequar a produção, em específico à sua capacidade produtiva, para conseguir acompanhar tal crescimento. Determinar um nível ótimo de capacidade para atender a demanda é fundamental para o desempenho do sistema produtivo (ALMEIDA; ROMANZINI; WERNER, 2016), em que "o desafio repousa sobre harmonizar o grau de capacidade de produção com o nível de demanda do mercado, visando a maximização dos lucros" (HO; FANG, 2013).

Como suporte ao planejamento da capacidade, tem-se o estudo de tempos, conceituado por Razmi e Shakhs (p.3, 2008) como um "procedimento para a melhoria da produtividade ao estabelecer padrões de tempo e classificar os movimentos utilizados ou necessários para executar uma determinada série de operação e atribuindo padrões de tempo predeterminados para estes movimentos".

Considerando-se a importância do planejamento da capacidade, esta pesquisa foi desenvolvida na Etapa de Cortes de uma Indústria Frigorífica de frangos, na linha que realiza o porcionamento das asas. A Porcionadora Dupla, uma das máquinas que realiza este porcionamento, não tem um aproveitamento ideal, principalmente quando se aumenta sua frequência de operação, pois isto dificulta a execução do trabalho dos colaboradores que têm a função de preencher as taliscas da Máquina (suportes nos quais as asas são encaixadas).

Desta forma, o objetivo deste trabalho consiste em planejar a capacidade da Porcionadora Dupla de asas na Etapa de cortes da Indústria Frigorífica, tendo como suporte o estudo de tempos, de modo a atender ao plano de produção da Empresa, bem como suas demandas produtivas. Para tal, faz-se necessário atingir os seguintes objetivos específicos: i) descrever o processo de porcionamento das asas de frango, realizado pela Porcionadora Dupla; ii) realizar o estudo de tempos e definir o tempo de operação para colocar as asas nas taliscas da Porcionadora Dupla; iii) calcular a capacidade produtiva (disponível, efetiva e realizada) da mão de obra e verificar se atende ao plano de produção da Empresa; iv) calcular a capacidade produtiva (disponível, efetiva e realizada) da Porcionadora Dupla e verificar se atende as demandas produtivas; v) calcular os índices de capacidade da mão de obra e da Porcionadora Dupla de asas; e, vi) determinar o padrão ideal de operação da Porcionadora Dupla, com base na quantidade de colaboradores e na frequência de operação da mesma.

Sendo assim, justifica-se o planejamento da capacidade da Máquina Porcionadora Dupla pelo fato da existência de um acúmulo de asas na calha de abastecimento da mesma, em que se conhecendo sua real capacidade é possível 
realizar adequações no processo produtivo para atender a demanda. Assim, é possível criar estratégias para o planejamento da produção, definição de carga homem e carga máquina, indicadores de disponibilidade e utilização.

\section{REFERENCIAL TEÓRICO}

\section{CAPACIDADE PRODUTIVA}

Toda empresa, independente do ramo de atuação, tem uma capacidade produtiva calculada com base em unidades de produção ao longo de determinado período de tempo, ou seja, quantos itens são possíveis fabricar tomando-se como medidas as horas, turnos, dias, semanas ou meses. Na literatura, estudos relevantes envolvem tais cálculos (CASTRO, 2018; PINHEIRO; PEREIRA JÚNIOR; VINCENZI, 2017; MOTTA; GOMES, 2016; PACHECO et al., 2012; TAMBORLIM et al., 2012; STAUDT; COELHO; GONÇALVES, 2011), visto que quando o assunto é planejar a capacidade produtiva, é fundamental ter informações que permitam a tomada de decisões assertivas, a fim de que haja o correto dimensionamento do de insumos e recursos.

Têm-se diferentes tipos de capacidade que devem ser analisadas, que, conforme Peinado e Graeml (2007) são classificadas em: i) Capacidade Instalada (Cl); ii) Capacidade Disponível ou de projeto (CD); iii) Capacidade Efetiva ou Carga (CE), e; iv) Capacidade Realizada (CR).

$\mathrm{A} \mathrm{Cl}$ refere-se ao volume máximo que uma unidade produtora pode alcançar, trabalhando em regime full time e desconsiderando qualquer tipo de perda (PEINADO; GRAEML, 2007). De acordo com Staudt, Coelho e Gonçalves (2011), por ser uma medida teórica, normalmente, a $\mathrm{Cl}$ não é utilizada para informações práticas sobre a capacidade de produção, tendo em vista que, ela fornece a produção, com a fábrica operando 24 horas por dia nos 7 dias da semana.

Conforme Staudt, Coelho e Gonçalves (2011), a CD é definida como a quantidade máxima que se pode produzir dentro da jornada de trabalho, a qual é obtida por meio da divisão da Carga Horária (CH) pelo Tempo Padrão (TP) de operação de um determinado produto (Equação 1).

$$
C D=C H / T P
$$

A CE desconta da carga horária diária de trabalho as diversas paradas programadas que podem existir, e esta subtração das paradas programadas da carga horária de trabalho resulta nas horas disponíveis para a produção (STAUDT; COELHO; GONÇALVES, 2011). Sendo assim, para Peinado e Graeml (2007), a CE tem relação com a CD, no entanto, são consideradas as Perdas Planejadas (PP) no cálculo (Equação 2).

$$
C E=C D-P P
$$

A CR é a capacidade que se aproxima do real, pois conforme Peinado e Graeml (2007), em seu cálculo, são subtraídos da CE as Perdas não Programadas (PnP) (Equação 3).

$$
C R=C E-P n P
$$




\section{Índices de Capacidade}

Para Slack et al. (2009), os índices de capacidade, indicam o desempenho da capacidade produtiva das organizações, em que é possível determinar se a capacidade na empresa está ocorrendo de forma adequada; sendo classificados em: i) Índice de Eficiência (IE), e; ii) Índice de Utilização (IU).

Segundo Peinado e Graeml (2007), o IE demonstra o percentual de eficiência da unidade produtora em realizar o trabalho programado (Equação 4) e, o IU demonstra o percentual de uso da CD (Equação 5).

$$
I E=C R / C E
$$

$$
I U=C E / C D
$$

\section{ESTUDO DE TEMPOS}

O estudo de tempos tem sido amplamente empregado na literatura (BARBOSA et al., 2017; PINHEIRO; PEREIRA JÚNIOR; VINCENZI, 2017; LACERDA et al., 2017; MARTINS et al., 2015; VIEIRA et al., 2015; LEITE et al., 2014), em diversos processos e setores distintos, quando há necessidade de melhorar a produtividade, entender detalhadamente o que ocorre no processo, a real capacidade de produção, eficiência do balanceamento, pontos de ineficiência, interações entre os postos de trabalho, desperdícios de tempo etc.

No estudo de tempos, por meio de cronometragens, determina-se o tempo médio de execução de uma tarefa e, a esse tempo médio deve-se acrescentar tempos elementares, como pausas, tempo de espera, entre outros, para então resultar em um tempo denominado de Tempo Padrão (TP) (CHIAVENATO, 2003).

Para determinação do TP é necessário determinar o Número de ciclos a serem cronometrados (N) e o Tempo Normal (TN) de operação. Segundo Coelho et al. (2010), para determinar o N (Equação 6), tem-se como base um número de cronometragens preliminar.

$$
N=\left((Z \cdot R) /\left(E R \cdot D_{2} X^{-}\right)\right)^{2}
$$

Para tal, é necessária a escolha do coeficiente de Distribuição normal (Z) (Tabela 1), de acordo com a probabilidade que tenha o grau de confiabilidade que se deseja atingir; bem como a determinação da Amplitude da amostra (R); do Erro relativo da medida (ER); do Coeficiente em função do número de cronometragem realizadas preliminarmente $\left(D_{2}\right)$, conforme Tabela 2; e, da Média da amostra (X).

Tabela 1 - Coeficientes de distribuição normal

\begin{tabular}{cllllllllll} 
Probabilidade & $90 \%$ & $91 \%$ & $92 \%$ & $93 \%$ & $94 \%$ & $95 \%$ & $96 \%$ & $97 \%$ & $98 \%$ & $99 \%$ \\
\hline $\mathbf{Z}$ & 1,65 & 1,70 & 1,75 & 1,81 & 1,88 & 1,96 & 2,05 & 2,17 & 2,33 & 2,58
\end{tabular}

Fonte: Peinado e Graeml (2007) 
Tabela 2 - Coeficientes de cronometragem iniciais

\begin{tabular}{cccc}
$N$ & $D_{2}$ & $N$ & $D_{2}$ \\
2 & 1,128 & 9 & 2,970 \\
3 & 1,693 & 10 & 3,078 \\
4 & 2,059 & 11 & 3,173 \\
5 & 2,326 & 12 & 3,258 \\
6 & 2,534 & 13 & 3,336 \\
7 & 2,704 & 14 & 3,407 \\
8 & 2,847 & 15 & 3,472 \\
\hline
\end{tabular}

Fonte: Peinado e Graeml (2007)

De acordo com Peinado e Graeml (2007), o TN é definido como o tempo demandado por um operador para executar sua tarefa a uma velocidade normal. O tempo normal é obtido por meio de multiplicação do Tempo Cronometrado (TC) pela Velocidade do operador (V) (Equação 7).

$$
T N=T C \cdot V
$$

A avaliação da velocidade do operador depende da percepção de ritmo do analista do estudo de tempos. Sendo assim, conforme Barnes (2001), é possível avaliar o ritmo do operador, por meio do Sistema Westinghouse para avaliação do ritmo, o qual utiliza-se de quatro Atributos (A) para estimar a eficiência do operador: habilidade, esforço, condições e consistência (Tabela 3).

Tabela 3 - Sistema Westinghouse para avaliação do ritmo do operador

\begin{tabular}{|c|c|c|c|c|c|}
\hline \multicolumn{3}{|c|}{ Habilidade } & \multicolumn{3}{|c|}{ Esforço } \\
\hline$+0,15$ & A1 & \multirow{2}{*}{ Super-hábil } & $+0,13$ & A1 & \multirow{2}{*}{ Excessivo } \\
\hline$+0,13$ & $\mathrm{~A} 2$ & & $+0,12$ & $\mathrm{~A} 2$ & \\
\hline$+0,11$ & B1 & \multirow{2}{*}{ Excelente } & $+0,10$ & B1 & \multirow{2}{*}{ Excelente } \\
\hline$+0,08$ & B2 & & $+0,08$ & B2 & \\
\hline$+0,06$ & C1 & \multirow{2}{*}{ Bom } & $+0,05$ & $\mathrm{C} 1$ & \multirow{2}{*}{ Bom } \\
\hline$+0,03$ & $\mathrm{C} 2$ & & $+0,02$ & $\mathrm{C} 2$ & \\
\hline 0,00 & $\mathrm{D}$ & Médio & 0,00 & $\mathrm{D}$ & Médio \\
\hline$-0,05$ & E1 & \multirow{2}{*}{ Regular } & $-0,04$ & E1 & \multirow{2}{*}{ Regular } \\
\hline$-0,10$ & E2 & & $-0,08$ & E2 & \\
\hline$-0,16$ & F1 & \multirow{2}{*}{ Fraco } & $-0,12$ & F1 & \multirow{2}{*}{ Fraco } \\
\hline$-0,22$ & $\mathrm{~F} 2$ & & $-0,17$ & $\mathrm{~F} 2$ & \\
\hline \multicolumn{3}{|c|}{ Condições } & \multicolumn{3}{|c|}{ Consistência } \\
\hline$+0,06$ & $A$ & Ideal & $+0,04$ & $A$ & Perfeita \\
\hline$+0,04$ & B & Excelente & $+0,03$ & B & Excelente \\
\hline$+0,02$ & $\mathrm{C}$ & Boa & $+0,01$ & $\mathrm{C}$ & Boa \\
\hline 0,00 & $\mathrm{D}$ & Média & 0,00 & $\mathrm{D}$ & Média \\
\hline$-0,03$ & $E$ & Regular & $-0,02$ & $E$ & Regular \\
\hline$-0,07$ & $\mathrm{~F}$ & Fraca & $-0,04$ & $\mathrm{~F}$ & Fraca \\
\hline
\end{tabular}

Fonte: Barnes (2001) 
Para o cálculo da V, de acordo com Coelho et al. (2010), deve-se realizar a somatória de $\mathrm{A}$ (Tabela 3) e somar o resultado a 1 (Equação 8).

$$
V=1+\Sigma A
$$

Conforme Peinado e Graeml (2007), para determinar o TP, deve-se levar em consideração que o operador não consegue manter o mesmo ritmo de trabalho o dia todo, devido a Fatores de Tolerância (FT) para atender às necessidades pessoais, alívio de fadiga e tempo de espera (Equação 9).

$$
T P=T N . F T
$$

O FT é calculado com base nos tempos livres que a empresa está disposta a conceder, sendo assim, determina-se a Porcentagem $(P)$ de tempo concedido em relação ao tempo de trabalho diário (Equação 10) (PEINADO; GRAEML, 2007).

$$
F T=1 /(1-P)
$$

\section{PROCEDIMENTOS METODOLÓGICOS}

\section{DESCRIÇÃO DA EMPRESA}

A Indústria Frigorífica de frangos está localizada na região norte central do Paraná. Nesta indústria são abatidos cerca de 12.000 frangos por hora. A Etapa de Cortes, em que foi desenvolvido o estudo, possui dois turnos de trabalho, sendo o horário do primeiro turno das 5:30h às 15:08h, e o segundo turno das $15: 30 \mathrm{~h}$ às $00: 42 \mathrm{~h}$. Para o desenvolvimento da pesquisa foram coletados dados do primeiro turno de trabalho, referentes a Máquina Procionadora Dupla, que fica na Linha da Asa, na Etapa de Cortes, da Empresa em estudo.

A Linha da Asa é responsável pela seleção de asas inteiras que serão comercializadas nos mercados interno e externo, e pelo corte das asas, o qual é feito em duas Máquinas: a Porcionadora Simples e a Porcionadora Dupla.

A Porcionadora Simples é abastecida pelas asas que vêm do Cone 1 e possui apenas uma linha de corte, já a Porcionadora Dupla é abastecida por asas que são provenientes dos Cones 2 e 3 e possui duas linhas de corte, ou seja, duas linhas com taliscas, nas quais as asas são encaixadas.

Sendo assim, por apresentarem demandas produtivas distintas e, a Porcionadora Dupla apresentar uma maior capacidade de corte, este trabalho tem como foco apenas o planejamento da capacidade desta Máquina e da mão de obra que a abastece.

Como as Linhas dos Cones 2 e 3 são capazes de produzir juntas 14.400 asas por hora, a Porcionadora Dupla deve ser capaz de atender esta demanda produtiva, de modo a evitar acúmulos de produtos.

No plano de produção da Empresa é definido que $70 \%$ do total de asas produzidas devem ser porcionadas, no entanto, não há uma especificação de quanto cada máquina deve produzir. Porém, para este trabalho, considerou-se que o porcionamento seja realizado apenas pela Porcionadora Dupla, tendo em vista que, na maioria das vezes, apenas essa Máquina está operando, enquanto a outra está desligada. 


\section{Realização do estudo de tempos e análise da operação}

Inicialmente, foi realizada a análise da operação de se colocar uma asa de frango na talisca da Máquina, em que se constatou a existência de dois padrões de operação. No $1^{\circ}$ padrão notou-se que o colaborador realiza a operação com apenas uma mão e no $2^{\circ}$ padrão é realizado com as duas mãos

A curvatura e inclinação da calha de abastecimento da Máquina, pela qual as asas chegam das linhas anteriores, não são ideais. Devido a isto, os colaboradores que ficam na extremidade da Máquina têm a necessidade de realizar uma operação a mais, ou seja, além de abastecer a Máquina com asas, eles puxam as asas desta calha, para deixar próximo ao corpo, na calha lateral.

Desta forma, foi constatada a existência do $3^{\circ}$ e $4^{\circ}$ padrões de operação. No $3^{\circ}$ padrão, o colaborador abastece as taliscas com uma mão e puxa as asas, e; no $4^{\circ}$, o colaborador abastece as taliscas com duas mãos e puxa as asas. Isto ocorre, pois há um revezamento de posição dos colaboradores sobre a Máquina.

Levando em consideração os diferentes padrões de operação observados, para a realização das cronometragens, houve a necessidade de usar distintas metodologias de cronometragens. Para tal, seguiram-se as instruções fornecidas pela Empresa em estudo (Quadro 1).

Quadro 1 - Descrição da cronometragem e cálculo do tempo cronometrado

\begin{tabular}{|c|c|}
\hline Atividade & Execução \\
\hline $\begin{array}{l}\text { Cronometrar } 6 \\
\text { asas }\end{array}$ & $\begin{array}{l}\text { Realizar } 15 \text { cronometragens da operação de se colocar } 6 \text { asas nas } \\
\text { taliscas (1ำ padrão). Realizar mesmo procedimento para 2ㅇ padrão }\end{array}$ \\
\hline $\begin{array}{l}\text { Cronometrar } 20 \\
\text { asas }\end{array}$ & $\begin{array}{l}\text { Realizar } 15 \text { cronometragens da operação de se colocar } 20 \text { asas nas } \\
\text { taliscas (3ำ padrão). Realizar mesmo procedimento para } 4 \text { 으 padrão }\end{array}$ \\
\hline $\begin{array}{l}\text { Parar cronômetro } \\
\text { digital }\end{array}$ & $\begin{array}{l}\text { Parar o cronometro quando o tempo de espera for superior a } 50 \% \\
\text { do tempo trabalhado, para qualquer cronometragem }\end{array}$ \\
\hline $\begin{array}{l}\text { Calcular tempo } \\
\text { cronometrado } \\
\text { para operação } \\
\text { com } 1 \text { mão }\end{array}$ & $\begin{array}{l}\text { i. Determinar o tempo médio da operação de se colocar uma asa } \\
\text { na talisca, com base nos dados obtidos na Atividade: } \\
\text { Cronometrar } 6 \text { asas ( } 1 \text { o padrão); } \\
\text { ii. Realizar o mesmo procedimento com os dados obtidos na } \\
\text { Atividade: Cronometrar } 20 \text { asas ( } 3 \text { o padrão); } \\
\text { iii. Determinar o tempo cronometrado por meio da média entre os } \\
\text { tempos obtidos nos itens i e ii. }\end{array}$ \\
\hline $\begin{array}{l}\text { Calcular tempo } \\
\text { cronometrado } \\
\text { para operação } \\
\text { com } 2 \text { mãos }\end{array}$ & $\begin{array}{l}\text { Realizar os mesmos procedimentos descritos anteriormente, no } \\
\text { entanto, considerar dados do } 2 \text { o e } 4 \text { o padrões para as execuções i) } \\
\text { e ii), respectivamente }\end{array}$ \\
\hline
\end{tabular}

Fonte: Autoria própria (2017)

Ressalta-se a existência de 4 padrões, em que o 10 e 20 padrões, durante as cronometragens das 6 asas excluíam a atividade de puxar a asas da calha, enquanto o 3 ㅇ e 4ㅇ padrões, durante as cronometragens das 20 asas, incluíam a atividade de puxar a asas da calha. Este procedimento foi realizado seguindo as instruções da Empresa. 
Após as cronometragens iniciais, calculou-se o Número de ciclos a serem cronômetros (N) (Equação 6). A coleta dos dados ocorreu em 4 períodos diferentes, sendo eles: às 7:00h, 9:45h, 11:30h e 14:45h. Em seguida, foram calculados os Tempos Normais (TN) e o Tempo Padrão (TP) (Equações 7 e 9, respectivamente).

\section{Realização dos cálculos da capacidade e do índice de capacidade}

No que diz respeito aos cálculos da capacidade da mão de obra, considerouse a carga horária do primeiro turno. Primeiramente, determinou-se a Capacidade Disponível (CD) (Equação 1).

Em seguida, definiu-se a Capacidade Efetiva (CE) e a Capacidade Realizada (CR) (Equações 2 e 3, respectivamente).

Foram consideradas como Perdas Planejadas (PP) as pausas de trabalho e como Perdas não Planejadas ( $\mathrm{PnP})$, as paradas não planejadas da Máquina, pois durante este período, os colaboradores param de realizar suas funções.

Para a determinação das $\mathrm{PnP}$, analisou-se em um período de 10 dias a quantidade de paradas e duração das mesmas.

Após os cálculos da capacidade da mão de obra, foi verificado se a mesma era capaz de atender ao plano de produção da Empresa.

Com relação aos cálculos da capacidade da Máquina, considerou-se a carga horária do primeiro turno. Primeiramente, determinou-se a CD da Máquina, seguindo as instruções da Empresa (Quadro 2).

Quadro 2 - Descrição das atividades necessárias para a determinação da quantidade de asas porcionadas por minuto

\begin{tabular}{|c|c|}
\hline Atividade & Execução \\
\hline $\begin{array}{c}\text { Realizar } \\
\text { cronometragem }\end{array}$ & $\begin{array}{l}\text { Realizar } 10 \mathrm{cronometragens} \mathrm{de} \mathrm{um} \mathrm{minuto} \mathrm{cada,} \mathrm{com} \mathrm{a} \mathrm{Máquina} \\
\text { operando a } 30 \mathrm{~Hz}\end{array}$ \\
\hline Contar taliscas & $\begin{array}{l}\text { Contar a quantidade de taliscas que entravam na Máquina durante } \\
\text { o período cronometrado. Estas correspondem a quantidade de } \\
\text { asas que podem ser porcionadas durante este período de tempo }\end{array}$ \\
\hline Variar frequências & $\begin{array}{l}\text { i. Repetir os procedimentos descritos na atividade: Realizar } \\
\text { cronometragem, porém com a Máquina operando a } 32 \mathrm{~Hz} \text {; } \\
34 \mathrm{~Hz} ; 36 \mathrm{~Hz} ; 38 \mathrm{~Hz} \text { e } 40 \mathrm{~Hz} \text {; } \\
\text { ii. Repetir os procedimentos descritos na atividade de Contar } \\
\text { taliscas. }\end{array}$ \\
\hline $\begin{array}{l}\text { Comparar a } \\
\text { relação entre } \\
\text { frequências e asas } \\
\text { porcionadas }\end{array}$ & $\begin{array}{l}\text { i. Elaborar Diagrama de dispersão com os dados obtidos nas } \\
\text { atividades anteriores; } \\
\text { ii. Gerar Equação de Tendência (ET) e coeficiente de correlação } \\
\text { das variáveis }\left(R^{2}\right) \text {; } \\
\text { iii. Analisar a correlação entre as variáveis. }\end{array}$ \\
\hline
\end{tabular}

Fonte: Autoria própria (2017)

Posteriormente, foram realizadas as cronometragens para a determinação da quantidade de taliscas que ficavam vazias, seguindo orientações da Empresa (Quadro 3). Estes dados foram utilizados para a determinação da CE da Máquina. 
Quadro 3 - Descrição das atividades necessárias para a determinação da quantidade de taliscas vazias.

\begin{tabular}{|c|c|}
\hline Atividade & Execução \\
\hline $\begin{array}{c}\text { Realizar } \\
\text { cronometragem }\end{array}$ & $\begin{array}{l}\text { Realizar } 10 \text { cronometragens de um minuto cada, com a Máquina } \\
\text { operando a } 30 \mathrm{~Hz} \text { e sendo abastecida por } 5 \text { colaboradores }\end{array}$ \\
\hline Contar taliscas & $\begin{array}{l}\text { Contar a quantidade de taliscas que entravam vazias na Máquina } \\
\text { durante o período cronometrado }\end{array}$ \\
\hline $\begin{array}{l}\text { Variar } \\
\text { frequências }\end{array}$ & $\begin{array}{l}\text { i. Repetir os procedimentos descritos na atividade de realizar } \\
\text { cronometragem, porém com a Máquina operando a } 32 \mathrm{~Hz} \text {; } \\
34 \mathrm{~Hz} ; 36 \mathrm{~Hz} ; 38 \mathrm{~Hz} \text { e } 40 \mathrm{~Hz} \text {; } \\
\text { ii. Repetir os procedimentos descritos na atividade de contar } \\
\text { taliscas. }\end{array}$ \\
\hline $\begin{array}{l}\text { Comparar a } \\
\text { relação entre } \\
\text { frequência e } \\
\text { taliscas vazias }\end{array}$ & $\begin{array}{l}\text { i. Elaborar Diagrama de dispersão com os dados obtidos nas } \\
\text { atividades anteriores; } \\
\text { ii. Gerar ET e R²; } \\
\text { iii. Analisar a correlação entre as variáveis. }\end{array}$ \\
\hline
\end{tabular}

Fonte: Autoria própria (2017)

Após, determinou-se a média de taliscas que cada colaborador deixava de abastecer. E então se definiu a quantidade de asas que deixaria de ser porcionada, caso a Porcionadora Dupla estive sendo operada por 4 ou 6 colaboradores.

Em seguida, definiu-se a CE e a CR da Máquina (Equações 2 e 3, respectivamente). Para isto, considerou-se a possibilidade de a Máquina ser abastecida por 4, 5 ou 6 colaboradores. Foram consideradas como PP as pausas de trabalho, e a quantidade de taliscas que deixavam de ser preenchidas na Porcionadora Dupla, para cada uma das possibilidades. E como PnP, as paradas não planejadas da Máquina.

Após os cálculos da capacidade da Máquina, foi verificado se a mesma era capaz de atender as demandas produtivas.

Posteriormente, foram calculados os Índices de Eficiência (IE) e de Utilização (IU) da Porcionadora Dupla e da mão de obra (Equações 4 e 5, respectivamente).

\section{Determinação do padrão de operação da Máquina}

Para a determinação do padrão de operação da Máquina, realizou-se a análise de diferentes variáveis (Quadro 4).

Quadro 4 - Descrição das atividades necessárias para a determinação do padrão de operação da Máquina.

\begin{tabular}{|c|c|}
\hline Atividade & Execução \\
\hline $\begin{array}{l}\text { Definir } \\
\text { quantidade de } \\
\text { colaboradores }\end{array}$ & $\begin{array}{l}\text { i. Analisar Capacidade realizada (CR) da mão de obra; } \\
\text { ii. Comparar com o Plano de Produção da Empresa; } \\
\text { iii. Determinar quantidade de colaboradores ideias para atender o } \\
\text { plano. }\end{array}$ \\
\hline $\begin{array}{l}\text { Analisar } \\
\text { velocidades dos } \\
\text { Cones } 2 \text { e } 3\end{array}$ & $\begin{array}{l}\text { i. Considerar possíveis velocidades dos Cones } 2 \text { e } 3 \text {; } \\
\text { ii. Determinar quantidade de asas enviadas por ambos os Cones } \\
\text { para a Máquina. }\end{array}$ \\
\hline $\begin{array}{c}\text { Relacionar } \\
\text { velocidade dos }\end{array}$ & $\begin{array}{l}\text { Comparar quantidade de asas enviadas pelos Cones à Máquina } \\
\text { com a sua CR nas diferentes frequências, sendo abastecida por } 4,5\end{array}$ \\
\hline
\end{tabular}




\begin{tabular}{|c|l|}
\hline $\begin{array}{c}\text { Cones com a } \\
\text { Máquina }\end{array}$ & ou 6 colaboradores \\
\hline $\begin{array}{c}\text { Analisar } \\
\text { resultados }\end{array}$ & $\begin{array}{l}\text { Definir a quantidade de colaboradores ideais para abastecer a } \\
\text { Máquina, de modo a atender a demanda produtiva proveniente } \\
\text { dos Cones }\end{array}$ \\
\hline
\end{tabular}

Fonte: Autoria própria (2017)

\section{RESULTADOS E DISCUSSÕES}

\section{DESCRIÇÃO DO PROCESSO DE PORCIONAMENTO DAS ASAS DE FRANGO}

A Empresa em estudo realiza as seguintes etapas no processamento dos frangos: i) Recepção; ii) Pendura; iii) Insensibilização e Sangria; iv) Escaldagem e Depenagem; v) Evisceração; vi) Cortes; vii) Embalamento secundário; viii) Congelamento; ix) Paletização; x) Estocagem, e; xi) Expedição.

Na Etapa de Cortes, ocorre a desossa da ave, em que, primeiramente, são removidas as pernas, para serem comercializadas com ou sem o osso; são removidas as asas, que são comercializadas inteiras ou porcionadas; em seguida, é removido o peito, o qual é vendido somente sem osso; e, por último, são removidos os filezinhos.

Com relação ao porcionamento das asas, elaborou-se um esquema que demonstra como as asas chegam até a Máquina Porcionadora Dupla (Figura 1).

Figura 1 - Esquema do processo de porcionamento das asas de frango realizado pela Máquina Porcionadora Dupla.

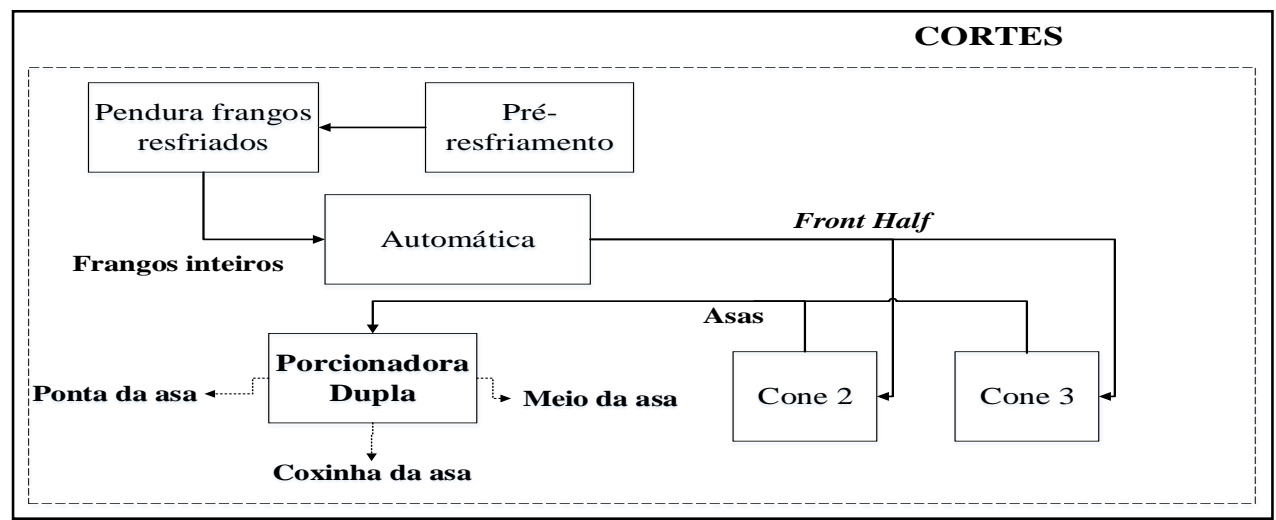

Fonte: Autoria própria (2017)

Inicialmente, os frangos passam por um processo de pré-resfriamento. Após, são penduradas e seguem por uma nória até a Máquina Automática que realiza o corte do Front Half (parte superior do corpo da ave, que inclui asas e peito). Após, segue por uma esteira até os Cones 2 e 3 , os quais realizam o corte das asas.

As asas seguem por uma esteira e chegam na calha de abastecimento que fica no início da Máquina. Após isto, as asas caem nas calhas laterais da Máquina e são abastecidas nas taliscas pelos colaboradores. 


\section{Análise dos padrões de operação}

Após a análise dos padrões de operação de colocar asas de frango nas taliscas, foi possível realizar a descrição detalhada do 1으 padrão (Quadro 5); 2 은 padrão (Quadro 6); 3o padrão (Quadro 7); 4ㅇ padrão (Quadro 8).

Quadro 5 - Descrição da operação de colocar asas de frango na talisca, com apenas uma mão (1ㅇp padrão)

\begin{tabular}{|c|c|c|c|}
\hline $\mathbf{N}^{\circ}$ & $\begin{array}{c}\text { Descrição da atividade - Mão } \\
\text { esquerda }\end{array}$ & $\begin{array}{c}\text { Descrição da atividade - Mão } \\
\text { direita }\end{array}$ & $\mathbf{N}^{\circ}$ \\
\hline 1 & Pegar a asa na calha lateral da \\
Máquina & Aguardar & 1 \\
\hline 2 & Passar a asa para a mão direita & Agarrar o produto & 2 \\
\hline 3 & Aguardar & Encaixar a asa na talisca & 3 \\
\hline 4 & Aguardar & Voltar a mão próximo ao corpo & 4 \\
\hline
\end{tabular}

Fonte: Autoria própria (2017)

Quadro 6 - Descrição da operação de colocar asas de frango na talisca, com as duas mãos (2ำ padrão)

\begin{tabular}{|c|c|c|c|}
\hline $\mathbf{N}^{\circ}$ & $\begin{array}{c}\text { Descrição da atividade - Mão } \\
\text { esquerda }\end{array}$ & $\begin{array}{c}\text { Descrição da atividade - Mão } \\
\text { direita } \\
\end{array}$ & $\mathbf{N}^{\circ}$ \\
\hline 1 & $\begin{array}{c}\text { Pegar a asa na calha lateral da } \\
\text { Máquina }\end{array}$ & $\begin{array}{c}\text { Pegar a asa na calha lateral da } \\
\text { Máquina }\end{array}$ & 1 \\
\hline 2 & Encaixar a asa na talisca & Encaixar a asa na talisca & 2 \\
\hline 3 & Voltar a mão próximo ao corpo & Voltar a mão próximo ao corpo & 3 \\
\hline
\end{tabular}

Fonte: Autoria própria (2017)

Quadro 7 - Descrição da operação de colocar asas de frango na talisca, com apenas uma mão e puxar asas da calha de abastecimento (3ㅇ padrão)

\begin{tabular}{|c|c|c|c|}
\hline $\mathbf{N}^{\circ}$ & $\begin{array}{c}\text { Descrição da atividade - Mão } \\
\text { esquerda }\end{array}$ & $\begin{array}{c}\text { Descrição da atividade - Mão } \\
\text { direita } \\
\end{array}$ & $\mathbf{N}^{\circ}$ \\
\hline 1 & $\begin{array}{c}\text { Pegar a asa na calha lateral da } \\
\text { Máquina }\end{array}$ & Aguardar & 1 \\
\hline 2 & Passar a asa para a mão direita & Agarrar o produto & 2 \\
\hline 3 & Aguardar & Encaixar a asa na talisca & 3 \\
\hline 4 & Aguardar & Voltar a mão próximo ao corpo & 4 \\
\hline 5 & Bloquear passagem das asas & $\begin{array}{c}\text { Puxar asas da esteira para a calha } \\
\text { de abastecimento }\end{array}$ & 5 \\
\hline 6 & Puxar asas para a calha lateral & Puxar asas para a calha lateral & 6 \\
\hline
\end{tabular}

Fonte: Autoria própria (2017)

Quadro 8 - Descrição da operação de colocar asas de frango na talisca, com as duas mãos e puxar asas da calha de abastecimento (40 padrão)

\begin{tabular}{|c|c|c|c|}
\hline $\mathbf{N}^{\circ}$ & $\begin{array}{c}\text { Descrição da atividade - Mão } \\
\text { esquerda }\end{array}$ & $\begin{array}{c}\text { Descrição da atividade }- \text { Mão } \\
\text { direita }\end{array}$ & $\mathbf{N}^{\circ}$ \\
\hline 1 & Pegar a asa na calha & Pegar a asa na calha & 1 \\
\hline
\end{tabular}




\begin{tabular}{|c|c|c|c|}
\hline 2 & Encaixar a asa na talisca & Encaixar a asa na talisca & 2 \\
\hline 3 & Voltar a mão próximo ao corpo & Voltar a mão próximo ao corpo & 3 \\
\hline 4 & Bloquear passagem das asas & $\begin{array}{c}\text { Puxar asas da esteira para a calha } \\
\text { de abastecimento }\end{array}$ & 4 \\
\hline 5 & Puxar asas para a calha lateral & Puxar asas para a calha lateral & 5 \\
\hline
\end{tabular}

Fonte: Autoria própria (2017)

\section{Tempo Padrão (TP) de operação}

Para determinar o Número de ciclos a serem cronometrados (N) (Tabela 4), considerou-se a probabilidade de $95 \%$, com relação a Distribuição normal (Z). Posteriormente, determinou-se a Amplitude da amostra ( $R$ ); o Coeficiente em função do número de cronometragens realizadas preliminarmente $\left(D_{2}\right)$; o Erro relativo da medida (Er); e, a Média da amostra (X), para cada um dos padrões de operação. Observa-se que apenas para o 2 o padrão foram realizadas mais 6 cronometragens para completar os 21 ciclos.

Tabela 4 - Determinação do Número de ciclos a serem cronometrados (N) para cada padrão

\begin{tabular}{ccccccc} 
Padrão & $\mathrm{Z}$ & $\mathrm{R}$ & $D_{2}$ & $\mathrm{Er}$ & $\bar{X}$ & $\mathrm{~N}$ \\
1ㅇ & 1,96 & 0,19 & 3,472 & $5 \%$ & 0,95 & $\mathbf{5}$ \\
2ㅇ & 1,96 & 0,37 & 3,472 & $5 \%$ & 0,91 & $\mathbf{2 1}$ \\
3ㅇ & 1,96 & 0,44 & 3,472 & $5 \%$ & 1,72 & $\mathbf{8}$ \\
4ㅇ & 1,96 & 0,38 & 3,472 & $5 \%$ & 1,13 & $\mathbf{1 5}$ \\
\hline
\end{tabular}

Fonte: Autoria própria (2017)

De acordo com as instruções da Empresa em estudo, para determinar o TC, realizou-se a média entre as cronometragens das 6 e 20 asas, para a operação de se colocar as asas com uma mão, ou seja, uma média entre TC do 1ㅇ padrão e do 3o padrão. Este procedimento foi adotado, pois, havia a necessidade de considerar a operação de puxar as asas na calha de abastecimento, porém, como esta operação é realizada somente por dois colaboradores, considerar apenas este padrão de operação aumentaria o TC, bem como desconsiderá-la reduziria o tempo. Os mesmos procedimentos foram adotados para determinar o TC da operação de se colocar asas com as duas mãos (2ำ padrão e 4 으 padrão) (Tabela $5)$.

Tabela 5 - Determinação do Tempo Cronometrado (TC)

\begin{tabular}{lc}
\multicolumn{1}{c}{ Operação } & TC (s) \\
Abastecer asas na Máquina com 1 mão (1ํ e 3ำ padrão) & 1,25 \\
Abastecer asas na Máquina com 2 mãos (2ำ e 4ำ padrão) & 0,93 \\
Tempo médio cronometrado (s) & $\mathbf{1 , 0 9}$ \\
\hline
\end{tabular}

Fonte: Autoria própria (2017)

Para o cálculo do TN, primeiramente, realizou-se a avaliação do ritmo de velocidade dos colaboradores que abastecem a Máquina, com uma ou duas mãos (Tabela 6). 
Tabela 6 - Avaliação do ritmo de Velocidade do operador (V)

\begin{tabular}{|c|c|c|c|c|c|}
\hline Operação & Habilidade & Esforço & Condições & Consistência & $\begin{array}{c}\text { Fator de } \\
\text { ritmo }\end{array}$ \\
\hline 1ㅇ e 3ํ padrão & 0,11 & $-0,04$ & 0,02 & 0,01 & 1,10 \\
\hline 2 e 40 padrão & 0,08 & $-0,04$ & 0,02 & 0,01 & 1,07 \\
\hline Média & 0,10 & $-0,04$ & 0,02 & 0,01 & 1,09 \\
\hline
\end{tabular}

Fonte: Autoria própria (2017)

Posteriormente, calculou-se a Fator de Tolerância (FT) e o TP (Tabela 7), em que se constatou que o TP médio necessário para o abastecimento de uma asa de frango na talisca da Máquina é de 1,34 segundos.

Tabela 7 - Determinação do Tempo Normal (TN) e Tempo Padrão (TP) da operação

\begin{tabular}{ccccc} 
Operação & TC (s) & TN $(s)$ & FT & TP $(s)$ \\
1o e 3o padrão & 1,25 & 1,38 & 1,125 & 1,55 \\
2o e 4o padrão & 0,93 & 1,00 & 1,125 & 1,12 \\
Média & $\mathbf{1 , 0 9}$ & $\mathbf{1 , 1 9}$ & $\mathbf{1 , 1 2 5}$ & $\mathbf{1 , 3 4}$ \\
\hline
\end{tabular}

Fonte: Autoria própria (2017)

\section{ANÁLISE DA CAPACIDADE PRODUTIVA E DOS ÍNDICES DE CAPACIDADE}

Com relação à capacidade produtiva, optou-se por realizar análises referentes somente as Capacidades: Disponível (CD), Efetiva (CE) e, Realizada (CR), tendo em vista que a capacidade instalada, conforme Staudt et al. (2011), não é utilizada para informações práticas, por apresentar dados teóricos, os quais consideram uma produção de 24 horas por dia, os sete dias da semana. Desta forma, não é viável tal análise para tomadas de decisões.

\section{Capacidade Produtiva de mão de obra}

Os cálculos da CD, CE e CR, da mão de obra utilizada para operar a Máquina, estão apresentados em capacidade diária, semanal e mensal (Tabela 8). A média diária da CR é de 21.004 asas por dia, ou seja, este valor representa a quantidade de asas que cada colaborador tem em relação à sua capacidade de abastecer a Máquina ao longo de sua jornada de trabalho.

Tabela 8 - Capacidade produtiva da mão de obra: diária, semanal e mensal

\begin{tabular}{|c|c|c|c|c|}
\hline & Operação & CD (asas) & CE (asas) & CR (asas) \\
\hline \multirow[t]{3}{*}{ Dia } & Realizada com 1 mão (1ํ e 3 Padrão) & 20.017 & 17.698 & 17.609 \\
\hline & $\begin{array}{l}\text { Realizada com } 2 \text { mãos ( } 2 \text { e } 4 \text { ㅇ } \\
\text { Padrão) }\end{array}$ & 27.736 & 24.522 & 24.399 \\
\hline & Média & 23.877 & 21.110 & 21.004 \\
\hline \multirow[t]{3}{*}{ Semana } & Realizada com 1 mão (1ํ e 3 Padrão) & 100.085 & 88.488 & 88.043 \\
\hline & $\begin{array}{l}\text { Realizada com } 2 \text { mãos ( } 2 \text { e } 4 \text { ㅇ } \\
\text { Padrão) }\end{array}$ & 138.682 & 122.612 & 121.996 \\
\hline & Média & 119.384 & 105.550 & 105.020 \\
\hline Mês & Realizada com 1 mão (1ㅇ e 3ㅇ Padrão) & 400.340 & 353.951 & 352.173 \\
\hline
\end{tabular}




\begin{tabular}{|c|c|c|c|}
\hline Operação & CD (asas) & CE (asas) & CR (asas) \\
\hline $\begin{array}{l}\text { Realizada com } 2 \text { mãos ( } 2 \text { e } 4 \text { ㅇ } \\
\text { Padrão) }\end{array}$ & 554.728 & 490.449 & 487.985 \\
\hline Média & 477.534 & 422.200 & 420.079 \\
\hline
\end{tabular}

Fonte: Autoria própria (2017)

De acordo com o plano de produção da Empresa, o primeiro turno deve porcionar 118.570 asas por dia. Desta forma, considerando-se que a CR de cada colaborador é de abastecer 21.004 asas por dia, na Porcionadora Dupla, é possível determinar que são necessários 6 colaboradores para atender a este plano de produção. Atualmente, a Empresa possui em seu quadro de colaboradores, uma quantidade suficiente que permite a destinação de 6 colaboradores para abastecer a Máquina.

\section{Capacidade Produtiva da Máquina}

Com a média das cronometragens referente a quantidade de asas porcionadas por minuto, foi possível elaborar um Gráfico de Dispersão (Figura 2).

Figura 2 - Relação entre frequência de operação da Máquina e quantidade de asas porcionadas por minuto

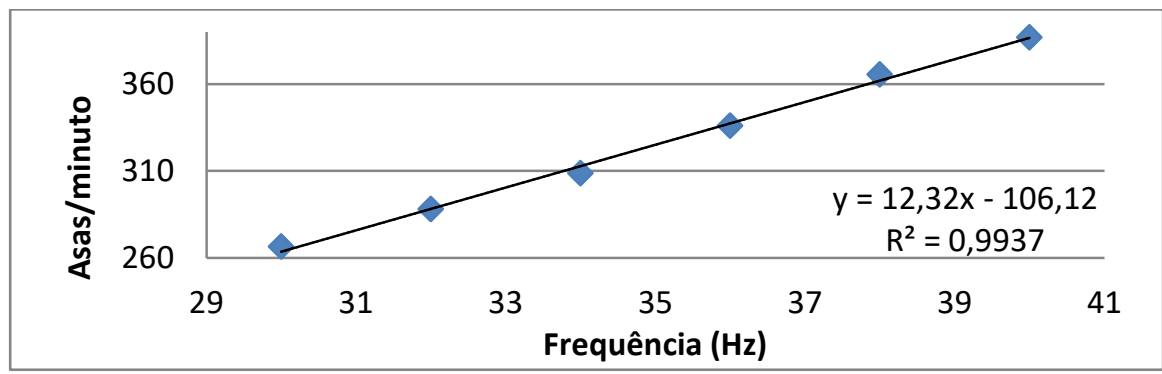

Fonte: Autoria própria (2017)

Como se pode observar (Figura 2) existe uma correlação entre frequência de operação da Máquina e a quantidade de asas porcionadas, pois, conforme Figueiredo Filho e Silva Júnior (2009), quando o $R^{2}$ aproxima-se de 1 há uma dependência estatística linear entre as variáveis. Isto significa que quando a frequência de operação da Máquina aumenta, ocorre o mesmo para a quantidade de asas porcionadas. Sendo assim, por meio desta relação foi gerada a Equação 11, com a qual é possível simular a quantidade de asas que são porcionadas (y), em uma determinada frequência de operação (x). Assim, caso a Máquina esteja operando a $45 \mathrm{~Hz}$, tem-se que serão porcionadas cerca de 448 asas por minuto.

$$
y=12,32 x-106,12
$$

Com a média das cronometragens referente a quantidade de taliscas vazias por minuto, foi possível elaborar o Gráfico de Dispersão (Figura 3), em que observa-se a correlação existente entre frequência de operação da Máquina e quantidade de taliscas vazias, pois, conforme aumenta-se sua frequência de operação, aumenta a quantidade de taliscas vazias.

Figura 3 - Relação entre frequência de operação da Máquina e taliscas vazias por minuto 


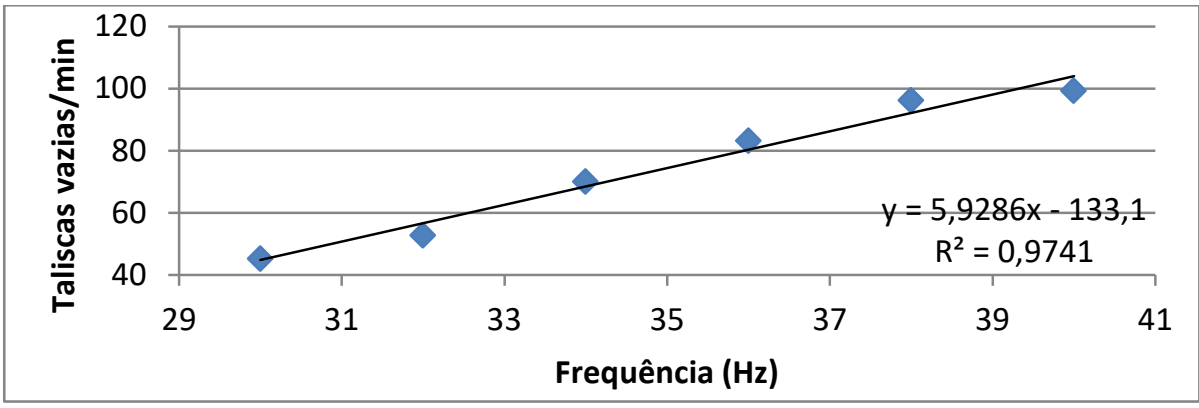

Fonte: Autoria própria (2017)

Sendo assim, por meio desta relação foi gerada a Equação 12, com a qual é possível simular a quantidade de asas que deixaram de ser porcionadas (y), em uma determinada frequência de operação da Máquina (x). Caso a Máquina esteja operando a $45 \mathrm{~Hz}$, sendo abastecida por 5 colaboradores, obtém-se que deixariam de ser porcionadas cerca de 134 asas por minuto. Em média, cada colaborador deixa de abastecer $9,11,14,17,19$ e 20 taliscas por minuto, com a Máquina operando a $30 \mathrm{~Hz}, 32 \mathrm{~Hz}, 34 \mathrm{~Hz}, 36 \mathrm{~Hz}, 38 \mathrm{~Hz}$ e $40 \mathrm{~Hz}$, respectivamente.

$$
y=5,9286 x-133,1
$$

Considerou-se a Frequência de Operação (FO) da Máquina, para a determinação da Capacidade Disponível (CD) da Porcionadora Dupla, bem como as suas Capacidades Efetiva (CE) e Realizada (CR), considerando a possibilidade da Máquina ser abastecida por 4, 5 ou 6 colaboradores. Os cálculos foram realizados para a capacidade diária, semanal e mensal (Tabela 9).

Tabela 9 - Capacidade produtiva da Máquina: diária, semanal e mensal

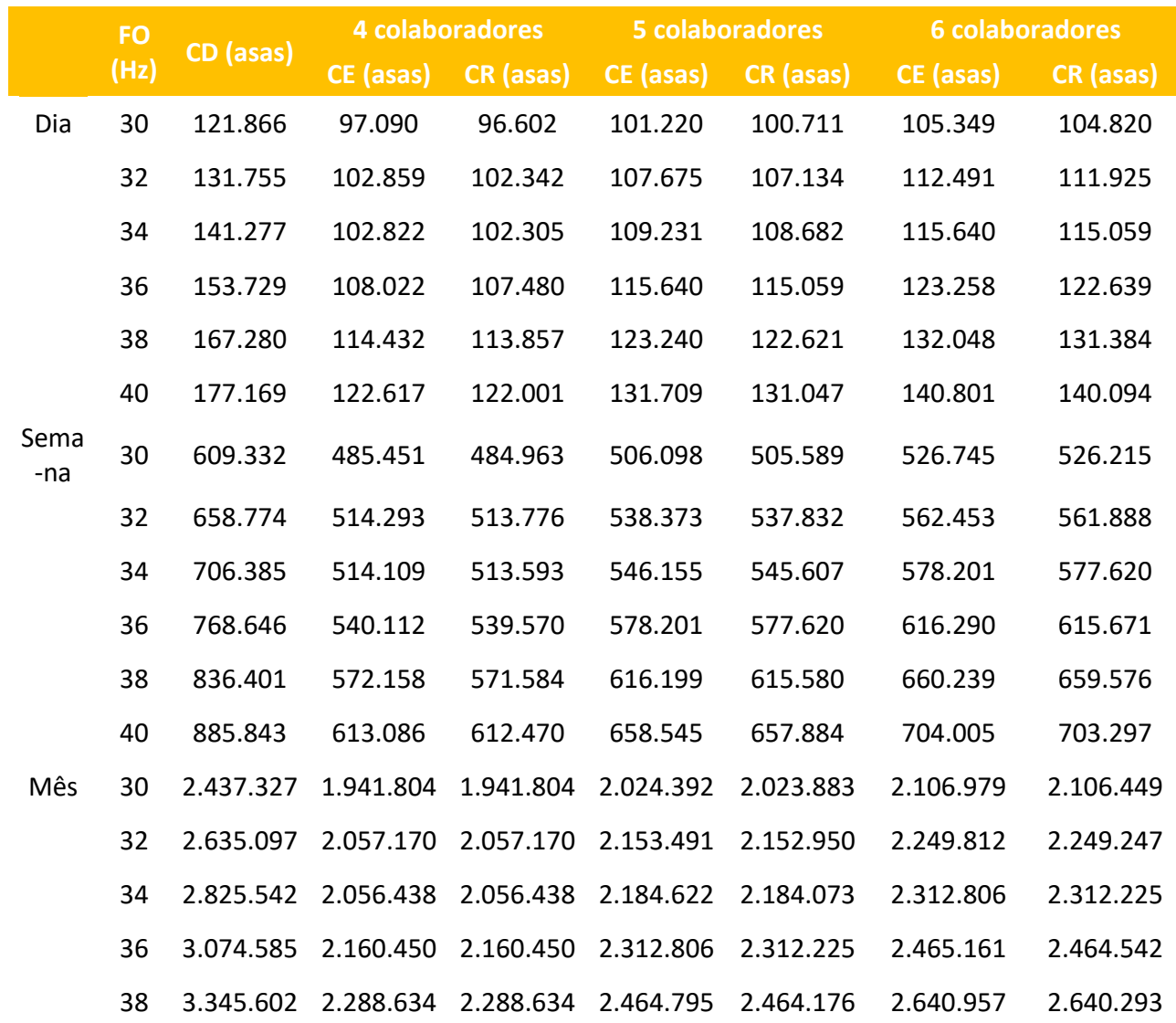




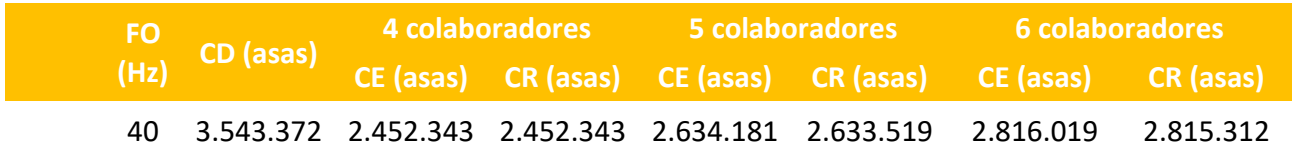

Fonte: Autoria própria (2017)

Observa-se (Tabela 9) que conforme aumenta a frequência de operação, maior é a capacidade produtiva da Máquina, ou seja, maior é a quantidade de asas que podem ser porcionadas. Isto ocorre independente da quantidade de colaboradores que estão abastecendo a Máquina, pois existe a correlação entre a frequência de operação da máquina e quantidade de asas porcionadas, como comprovado pelo Gráfico de Dispersão e $\mathrm{R}^{2}$ (Figura 2).

Ao se comparar a Quantidade de Asas (QA) enviadas para a Porcionadora Dupla diariamente, semanalmente e mensalmente, pelos Cones 2 e 3, a diferentes velocidades (VC) (Tabela 10), com sua CR, constata-se que a Máquina é capaz de atender as demandas produtivas. No entanto, isto é possível de ser alcançado com diferentes quantidades de colaboradores e frequência de operação da Máquina. Assim, é imprescindível a utilização do padrão de operação ideal para um melhor aproveitamento da Máquina e da mão de obra.

Tabela 10 - Quantidade de asas enviadas pelos Cones 2 e 3 para a Porcionadora Dupla

\begin{tabular}{cccc} 
VC (front halff/min) & QA (asas/dia) & QA (asas/semana) & QA (asas/mês) \\
15 & 54.936 & 274.680 & 1.098 .720 \\
20 & 73.248 & 366.240 & 1.464 .960 \\
25 & 91.560 & 457.800 & 1.831 .200 \\
30 & 109.872 & 549.360 & 2.197 .440 \\
31 & 113.534 & 567.672 & 2.270 .688 \\
32 & 117.197 & 585.984 & 2.343 .936 \\
33 & 120.859 & 604.296 & 2.417 .184 \\
34 & 124.522 & 622.608 & 2.490 .432 \\
35 & 128.184 & 640.920 & 2.563 .680 \\
\hline
\end{tabular}

Fonte: Autoria própria (2017)

\section{Índices de capacidade da mão de obra e da máquina}

Após a realização dos cálculos da capacidade produtiva, foi possível determinar os Índices de Eficiência (IE) e Índices de Utilização (IU) da mão de obra e da Máquina.

Com relação a mão de obra, independente do padrão de operação adotado, os índices se mantiveram constante. Desta forma, tem-se que o IE encontrado foi de $99,04 \%$ e IU foi de $88,89 \%$, demonstrando assim, que o percentual de eficiência é satisfatório e que o percentual de uso apresenta um valor mais baixo, devido a necessidade da realização de pausas durante a jornada de trabalho, conforme regulamentado pela NR 36 - Segurança e Saúde no Trabalho em Empresas de Abate e Processamento de Carnes e Derivados.

No que diz respeito aos índices da Máquina, apenas o IE manteve-se constante, enquanto o IU sofreu variação (Figura 4). 
Figura 4 - Gráfico dos Índices de eficiência (IE) e Índices de utilização (IU) da Porcionadora Dupla

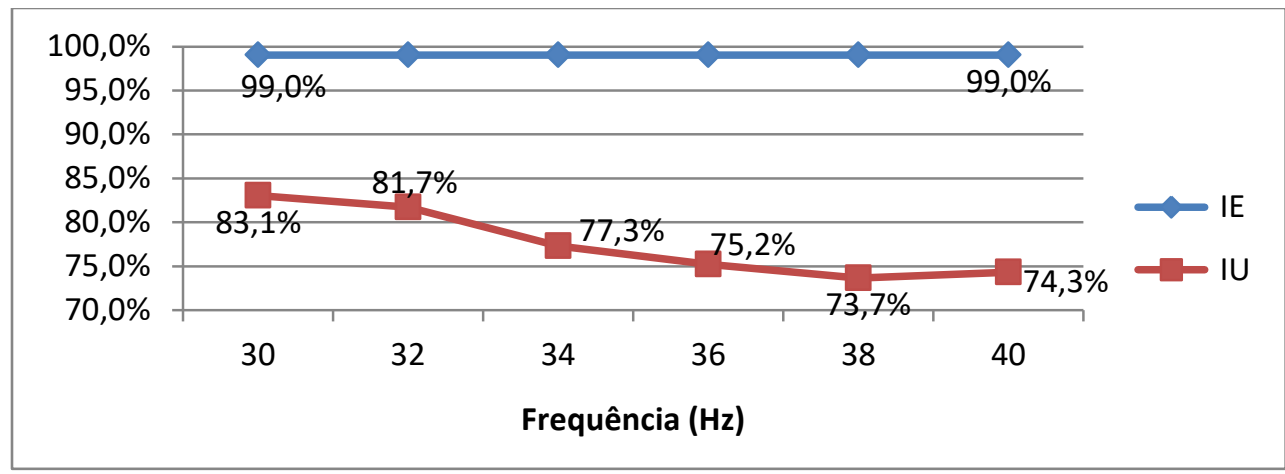

Fonte: Autoria própria (2017)

O IE se manteve constante independente da frequência de operação da Máquina (Figura 4), pois a taxa de Paradas não Programadas ( $\mathrm{PnP})$ é o mesmo para qualquer frequência. No entanto, com relação ao IU, o percentual de uso reduz conforme aumenta a frequência, devido à relação existente entre frequência de operação e quantidade de asas taliscas vazias (Figura 3), isto é, quanto maior a frequência menor é a quantidade de asas porcionadas. Somente na frequência de $40 \mathrm{~Hz}$ o IU apresentou crescimento, pois o aumento da quantidade de taliscas vazias nesta frequência não foi proporcional as demais frequências. Isto gerou um impacto menor sobre a Capacidade Disponível (CD) da Máquina, o que resultou em uma maior taxa de utilização da Porcionadora Dupla.

\section{PADRÃO DE OPERAÇÃO DA MÁQUINA}

Considerando o Tempo Padrão (TP = 1,34 s) de operação de se colocar as asas na Máquina, a Capacidade Realizada ( $C R=21.004$ asas por dia) da mão de obra e o plano de produção da empresa (porcionar 118.570 asas por dia), tem-se como ideal que a Máquina seja abastecida por 6 colaboradores, para conseguir atender ao plano de produção. No entanto, é necessário analisar outras variáveis presentes no processo, como velocidade dos Cones 2 e 3, a Quantidade de Asas (QA) que são enviadas para a Máquina e a capacidade produtiva da mesma, para definir-se o seu padrão de operação.

Mediante a isto, analisou-se a relação entre a Velocidade dos Cones 2 e 3 (VC), e a Frequência de Operação (FO) da Porcionadora Dupla, sendo abastecida por 4, 5 ou 6 colaboradores, para definir o padrão de operação da Máquina (Tabela 11), de modo a atender as demandas produtivas, ou seja, a QA enviadas para a Máquina durante o primeiro turno por ambos os Cones (Tabela 10).

Tabela 11 - Padrão de operação da Porcionadora Dupla

$\begin{array}{cccc}\text { VC front } & \text { FO com } 4 & \begin{array}{c}\text { FO com } 5 \\ \text { half/min) }\end{array} & \begin{array}{c}\text { FO com } 6 \\ \text { colaboradores }(\mathrm{Hz})\end{array} \\ 15 & 30 & 30 & 30 \\ 20 & 30 & 30 & 30 \\ 25 & 30 & 30 & 30 \\ 30 & 38 & 36 & 32\end{array}$




\begin{tabular}{cccc}
$\begin{array}{c}\text { VC firont } \\
\text { half/min) }\end{array}$ & colaboradores $(\mathrm{Hz})$ & $\begin{array}{c}\text { FO com } 5 \\
\text { colaboradores }(\mathrm{Hz})\end{array}$ & $\begin{array}{c}\text { FO com } 6 \\
\text { colaboradores }(\mathrm{Hz})\end{array}$ \\
31 & 38 & 36 & 34 \\
32 & 40 & 38 & 36 \\
33 & - & 38 & 36 \\
34 & - & 40 & 38 \\
35 & - & 40 & 38 \\
\hline
\end{tabular}

Fonte: Autoria própria (2017)

Como se pode observar (Tabela 11), a quantidade de 4 colaboradores abastecendo a Máquina é insuficiente para atender a demanda produtiva dos Cones, caso os mesmos estejam operando acima de 32 front half por minuto. No entanto, em situações adversas do dia a dia da Empresa, em que seja necessária uma redução na velocidade dos Cones, é indicado que a Máquina seja abastecido por 4 colaboradores, a fim de evitar ociosidade.

Caso os Cones 2 e 3 estejam a uma velocidade de até 25 front half por minuto, sugere-se a utilização de 4 colaboradores e a FO da Máquina conforme Tabela 11, tendo em vista que a CR da Máquina, sendo abastecido por 4 colaboradores é de 96.602 asas por turno, e a QA é de 91.560 asas por turno, demonstrando assim, que os 4 colaboradores serão suficientes para atender a demanda produtiva dos Cones 2 e 3 e evitar que haja acúmulo de produtos na calha de abastecimento.

Com a Máquina sendo abastecida por 5 ou 6 colaboradores é possível atender a demanda produtiva dos Cones a qualquer velocidade. No entanto, quando se tem 6 colaboradores, a frequência de operação da Máquina necessária para atender a esta restrição é menor, havendo, desta forma, uma exigência menor de rendimento da Porcionadora Dupla, e um aumento em seu IU (Índice de Utilização) (Figura 4).

Em situações normais diárias da Empresa, a VC mais utilizada é de 30 front half por minuto. Desta forma, como se tem que 6 colaboradores são suficientes para atender ao plano de produção da Empresa e a demanda produtiva dos Cones, sugere-se que a Porcionadora Dupla seja abastecida por esta quantidade de colaboradores e tenha sua FO controlada de acordo com a VC, como apresentado na Tabela 7. Por exemplo, se os Cones estiverem com velocidade de 30 front half por minuto, são enviadas 109.872 asas por turno para a Máquina. Portanto, a mesma deverá operar a $32 \mathrm{~Hz}$, pois a esta frequência possui a CR de 111.925 asas por turno, quando abastecida por 6 colaboradores. Isto demonstra que, na frequência de $32 \mathrm{~Hz}, 6$ colaboradores serão suficientes para atender a demanda produtiva dos Cones 2 e 3 e evitar que haja acúmulo de produtos na calha de abastecimento.

\section{CONSIDERAÇÕES FINAIS}

A utilização do planejamento da capacidade, em conjunto com o estudo de tempos, permitiu, por meio do estudo em um Frigorífico de frangos, promover resultados que acarretaram aos objetivos propostos nesta pesquisa. Nesse sentido, este artigo teve por intuito ampliar os estudos acerca do planejamento 
da capacidade, a fim de proporcionar aos gestores da Empresa um maior conhecimento da capacidade produtiva da Máquina Porcionadora Dupla, contribuindo com informações importantes que possam ser aplicadas para a melhoria do desempenho produtivo da Organização.

A Empresa não possuía um estudo que validasse a capacidade da Máquina e que apresentasse um padrão de operacionalização da mesma, o que contribuía para o acúmulo de asas na calha de abastecimento da Máquina, devido a existência de diferentes formas de execução da atividade de abastecê-la (4 padrões) e as suas variações de capacidade, conforme a frequência de operação.

Com a realização deste estudo, pode-se concluir que a Máquina possui capacidade para atender a demanda produtiva, e o plano de produção da Empresa, desde que seja cumprido o padrão de operação, no qual, definiu-se que 6 é a quantidade ideal de colaboradores para a Máquina operar, e que a frequência de operação deve ser seguida, de acordo com a velocidade dos Cones 2 e 3, garantindo assim, que se tenha um melhor aproveitamento do uso da Máquina.

Ressalta-se que por meio do planejamento da capacidade, a Empresa se torna mais competitiva, pois garantirá o cumprimento do plano de produção, e consequentemente o atendimento a demanda, sem atrasos na entrega de seus produtos. Além de fazer o uso adequado de seus recursos produtivos, como mão de obra e Máquina.

Sugere-se que, em trabalhos futuros, sejam analisadas a relação entre o padrão de operacionalização da Máquina e o seu padrão de corte, isto é, que seja verificado, se quando a quantidade de colaboradores que abastecem a Porcionadora Dupla e a frequência de operação são alteradas, ocorre alguma modificação na aparência do corte das asas. 


\title{
Capacity planning: a case study at the cutting stage of a chicken fridge
}

\begin{abstract}
The present work has the objective of planning the capacity of the Double Wing Cutter Machine, in the Cutting Stage, of a Fridge Industry, having as support the study of times. First, the standard time to put a wing on the Machine was defined and compared to the Company's production plan. Then, the calculations of the capacity (available, effective and fulfilled), workforce and the Machine were performed. Finally, all these variables were related, to then define the machine's ideal operating standard, which included the number of employees and frequency of operation of the Machine, in order to meet the productive demands. With the accomplishment of the planning of the capacity of the Machine, it was verified its has sufficient capacity to attend to the production plan of the Company and the productive demands. In order to guarantee this, it is necessary to comply with the Machine's operating standard, in which it was possible to define the quantities of collaborators needed to supply the Machine, operating at a defined frequency according to the speed of the lines preceding it.
\end{abstract}

KEYWORDS: Time study. Manpower capacity. Machine capacity. 
ALMEIDA, R. P.; ROMANZINI, F.; WERNER, L. Planejamento da capacidade de produção na indústria plástica: uma abordagem baseada em previsão de demanda e níveis de capacidade. Revista Produção online, v.16, n.3, p.10331057, 2016. crossref

BARBOSA, S. N. S.; CAVALCANTE, . G. L.; SILVA, F. F.; NEGRÃO, L. L. L.; SANTOS, L. O. Estudos de tempos: análise da capacidade produtiva da operação da produção de picolés. Revista Latino-Americana de Inovação e Engenharia de Produção, v. 5. n. 8. p. 56-76, 2017. crossref

BARNES, R. Estudo de Movimentos e de Tempos, Projeto e Medida do Trabalho. São Paulo: Edgard Blücher, 2001.

CASTRO, T. R. Planejamento e controle da produção em uma indústria de margarinas. Revista Gestão Industrial, Ponta Grossa, v. 14, n. 3, p. 1-22, jul./set. 2018. crossref

CHIAVENATO, I. Introdução à teoria geral da administração: uma visão abrangente da moderna administração das organizações. 7. ed. Rio de Janeiro: Elsevier, 2003.

COELHO, G, F.; BORDALO, A. C.; PINHEIRO, E. S.; PETROLI, P. H. B.; NOGUEIRA, L. R. (2010). Um Estudo de Tempos e Determinação de Capacidade Produtiva em um Processo de Envase de Azeitonas em uma Empresa de Alimentos. In: Encontro Nacional de Engenharia de Produção, 30, 2010, São Carlos, SP. Anais. São Paulo: ENEGEP, 2010.

Confederação da Agricultura e Pecuária do Brasil, CNA Brasil. Balanço 2016: Perspectivas 2017. 2017. Disponível em: <http://www.cnabrasil.org.br/sites/default/files/sites/default/files/uploads/15 a vicultura.pdf>. Acesso em 07 de outubro de 2018.

FIGUEIREDO FILHO, D. B.; SILVA JÚNIOR, J. A. Desvendando os Mistérios do Coeficiente de Correlação de Pearson (r). Revista Política Hoje, v.18, n.1, p.115146, 2009.

GONÇALEZ, P. U.; WERNER, L. Comparação dos índices de capacidade do processo para distribuições não-normais. Gestão \& Produção, v.16, n.1, p.121132, 2009. crossref 
HO, J.; FANG, C. Production capacity planning for multiple products under uncertain demands conditions. International Journal Production Economics, v. 141, n.1, p.593-604, 2013. crossref

LACERDA, M. S.; SOUSA, S. R. O.; LAMEIRA, I. W. A.; CAMPOS, E. M. R.; OLIVEIRA, R. D. O papel do estudo de tempos e movimentos na gestão da inovação: Um estudo aplicado na operação de equipamentos móveis de uma planta industrial portuária. Revista Espacios, v. 38, n. 23, 2017.

LEITE, E. S.; FERNANDES, H. C.; GUEDES, I. L.; AMARAL, E. J. Análise técnica e de custos do corte florestal semimecanizado em povoamentos de eucalipto em diferentes espaçamentos. CERNE, Lavras , v. 20, n. 4, p. 637-643, 2014. crossref

LINGITZ, L.; MORATEWETZ, C.; GIGLOO, D. T.; MINNER, S.; SIHN, W. Modelling of flexibility costs in a decision support system for midterm capacity planning. Procedia CIRP 7, 46th CIRP Conference on Manufacturing Systems, (pp.539 544), Elsevier, 2013. crossref

MARTINS, V. W. B.; LIMA, I. D. A.; SILVA, J. C. K.; BERNARDES, K. D.; DINIZ, M. F. S. Utilização do estudo de tempos cronometrados para determinação da capacidade produtiva de um salão de beleza. Produção em Foco, v. 5, n.1, 2015. crossref

MOTTA, M. P. O.; GOMES, J. P. H. Capacidade Produtiva e Eficiência de Processo: um Estudo de Caso em uma Confecção de Moda Fitness. Revista Interdisciplinar do Pensamento Científico, v. 2, n. 2, 2016. crossref

PACHECO, D. A. J.; ANTUNES JÚNIOR, J. A. V.; LACERDA, D. P.; GOLDMEYER, D. B.; GILSA, C. V. Modelo de Gerenciamento da Capacidade Produtiva: integrando Teoria das Restrições e o Índice de Rendimento Operacional Global (IROG). Revista Produção Online, Florianópolis, SC, v.12, n. 3, p. 806-826, jul./set. 2012. crossref

PEINADO, J.; GRAEML, A. R. Administração da Produção: Operações Industriais e de Serviços. Curitiba: UnicenP, 2007.

PINHEIRO, L. P.; PEREIRA JÚNIOR, E. H.; VINCENZI, S. L. Desenvolvimento de uma ferramenta para análise da capacidade produtiva de uma indústria de móveis de aço com a utilização de Estudo dos Tempos e Métodos. Revista Espacios, v. 38, n. 41, 2017. 
RAZMI, J.; SHAKHS, N. M. Developing a specific predetermined time study approach: an empirical study in a car industry. Prod. Plan. Control Manag. Operations, v.19, n.5, p.454-460, 2008. crossref

SLACK, N.; CHAMBERS, S.; JOHNSTON, R. Administração da produção. 3. ed. São Paulo: Atlas, 2009.

STAUDT, F, H.; COELHO, A, S.; GONCALVES, M, B. Determinação da capacidade real necessária de um processo produtivo utilizando cadeia de Markov.

Production, v.21, n.4, p.634-644, 2011. crossref

VIEIRA, R. R. S.; CORREIA, A. M. M.; LUCENA, A. D.; SILVA, A. M. Estudo de Tempos e Métodos no Processo Produtivo de uma Panificadora Localizada em Mossoró/RN. Revista Eletrônica Gestão \& Sociedade, v.9, n.23, p. 977-999, 2015. crossref

TAMBORLIM, N.; HAYDE, C. T. V. D.; SCHIMITT, C. S.; HEIDEN, G.; DALFOVO, O. A Capacidade de Produção como Recurso Gerador de Ganhos. R. eletr. estrat. neg., Florianópolis, v.5, n.3, p.28-56, set./dez. 2012 crossref

ALMEIDA, D.M. et al. Planejamento da capacidade: um estudo de caso na etapa de cortes de um frigorífico de frangos. R. Gest. Industr., Ponta Grossa, v. 16, n. 2, p. 79-101, Abr./Jun. 2020. Disponível em: https://periodicos.utfpr.edu.br/revistagi

Correspondência:

Danieli Martins de Almeida

Universidade Estadual do Paraná (UNESPAR), Campo Mourão, Paraná, Brasil.

Direito autoral:Este artigo está licenciado sob os termos da Licença Creative Commons-Atribuição 4.0

Internacional. 